\title{
REPRESENTAÇÕES SEMIÓTICAS NO GÊNERO REPORTAGEM EM REVISTAS PORTUGUESAS
}

\author{
Audria Albuquerque Leal ${ }^{\star}$ \\ Universidade Nova de Lisboa \\ Centro de Linguística \\ Fundação para a Ciência e Tecnologia \\ Lisboa, PT
}

\begin{abstract}
Resumo: Este artigo objetiva estudar representações semióticas no gênero reportagem. Para isso, analisa dois textos deste gênero textual de duas revistas portuguesas: Visão e Sábado. Para esta análise, segue as propostas teóricas do Interacionismo Sociodiscursivo e da Semiótica Social, incluindo o quadro metodológico da Gramática do Design Visual. Desta forma, o presente artigo procura levar em consideração o papel do não verbal no gênero reportagem e sua relação com a função social do gênero. Os resultados indicam que os significados das representações são construídos a partir das práticas sociais para atender a função comunicativa do gênero.
\end{abstract}

Palavras-chave: Texto. Multimodalidade. Gênero. Semiótica social. Interacionismo sociodiscursivo.

1 INTRODUÇÃO

Com o surgimento das novas tecnologias nas sociedades modernas, cada vez mais o visual participa nas ações comunicativas. De facto, é possível verificar a abundância do uso do não verbal em textos que circulam entre os mais diversos grupos sociais e, principalmente, nos que requerem uma maior velocidade no processo de leitura. Enfim, a sociedade é diariamente "inundada" de textos com imagens. Esta constatação revela uma mudança de paradigma nos processos interpretativos que os estudiosos da área dos textos e dos discursos não podem ignorar. Para Kress (1997), a linguística deve procurar responder às práticas, preocupações e necessidades no uso da linguagem em nossos dias. E, sem dúvida, no uso da língua, o verbal interage com o não verbal. Portanto, analisar a relação entre os diferentes modos semióticos é essencial se quisermos entender como se processa a comunicação em nossos dias. Por outro lado, é consensual a ideia de que os textos se realizam segundo um modelo de gênero textual. A noção de gênero está relacionada com a diversidade das práticas sociais, ou seja, os gêneros apresentam características sociocomunicativas variáveis de acordo com as necessidades comunicativas humanas. Isto significa que estudar gêneros textuais é analisar todos os aspectos que compõem esse objeto de estudo, desde os processos particulares de produção, distribuição e consumo, até as categorias composicionais, sejam verbais ou

\footnotetext{
* O presente trabalho foi financiado por Fundos Nacionais através da FCT - Fundação para a Ciência e Tecnologia (Portugal), no âmbito do projeto UID/LIN/03213/2013 e do projeto SFRH/BPD/111234/2015. E-mail: audrialeal@fcsh.unl.pt
} 
visuais. Isto é, desde os aspectos relacionados ao contexto, até os aspectos relacionados com a representação destes contextos em suas categorias semiotizadas pela linguagem.

Diante desta problemática relacionada com os estudos dos gêneros textuais, seja na caracterização do gênero seja na sua ação social, o presente artigo procurará ter em consideração o papel do não verbal no género reportagem e na relação deste papel com a função social do gênero, principalmente nos processos interpretativos. Deste modo, fundamentamos o trabalho a partir de dois pressupostos: 1) A interação humana é estabelecida através de textos e sua realização se manifesta por meio de gêneros textuais, sejam orais ou escritos; 2) uma análise textual que parte da observação empírica de textos/gêneros deve considerar a relação de todos os elementos verbais e não verbais que compõem o objeto de estudo. Portanto, o texto, como manifestação de um gênero, será considerado neste artigo como sendo multimodal, pois convoca não só o verbal mas também outros elementos semióticos. A partir destas considerações, o objetivo deste trabalho é analisar o papel das representações semióticas, narrativas e conceituais, no gênero reportagem. A escolha da reportagem, um gênero reconhecidamente multimodal, foi determinada pela hipótese de poder funcionar como exemplo que nos permite analisar o papel que o não verbal vem desempenhando nos textos produzidos nas sociedades modernas.

Teremos como base dois quadros teórico-metodológicos. O primeiro é o do Interacionismo Sociodiscursivo, proposto por Bronckart (1999 e 2008), assumindo que, através deste quadro, podemos observar os efeitos das situações de comunicação no funcionamento linguístico. O segundo é voltado para a análise do não verbal, sendo esta análise orientada pelo quadro teórico-metodológico criado pelos autores Kress e van Leeuwen (2006) e apresentado na obra The Grammar of Visual Design (A Gramática do Design Visual). A perspectiva teórica e metodológica desses autores recupera as três metafunções propostas por Halliday (1978), interpessoal, ideacional e textual, e as aplica às análises de textos multimodais, procurando interpretar experiências e formas de interação social dentro de uma perspectiva semiótica. Assim, Kress e van Leeuwen (1996/2006) produzem outras três (meta)funções distintas que serão denominadas significados; são elas: a representacional, a interacional e a composicional. $\mathrm{O}$ foco do presente artigo é a função representacional e seu papel no processo interpretativo do gênero.

Para tal, escolheu-se trabalhar seis exemplares do género reportagem nas revistas publicadas em Portugal, Visão e Sábado, no mês de Novembro de 2015, sendo três exemplares de cada revista, três reportagens da revista Visão e três da revista Sábado. Na impossibilidade de apresentar a análise de todos os exemplares estudados, centraremos nosso artigo em um exemplar representativo do género de cada uma das revistas.

No intuito de atingir nosso objetivo, em primeiro lugar apresentaremos o enquadramento teórico que fundamenta a análise. Em seguida, mostraremos a ocorrência da categoria Representacional Narrativa e Conceitual nas reportagens de capa das revistas Visão e Sábado, publicadas em Portugal; e, por fim, verificaremos o papel dessa categoria no processo interpretativo do gênero em análise. Com isso, esperamos tirar as ilações necessárias para compreender o funcionamento comunicativo da reportagem em sua vertente não verbal e conhecer os objetivos do uso da representação do visual pelo produtor. 
2 PRESSUPOSTOS TEÓRICOS 2.1 A NOÇÃO DE TEXTO MULTIMODAL E A RELAÇÃO COM A NOÇÃO DE GÊNERO TEXTUAL

A definição de gêneros como prática de linguagem que tem uma atuação social incide sobre o princípio de que a língua é uma produto social e, sendo assim, é sujeita às necessidades comunicativas do homem. Essa constatação está na base da ideia de que os gêneros apresentam características sociais e comunicativas que variam de acordo com a diversidade das atividades sociais do homem. Podemos mesmo afirmar que as práticas de linguagem estão associadas a uma diversidade de gêneros de textos próprios de cada esfera de atividades sociais. Dentro dessa linha de entendimento, Marcuschi (2002) evidencia que os gêneros se distribuem na oralidade e na escrita como práticas sociais sedimentadas longamente desenvolvidas e testadas. Os gêneros são de natureza sociocomunicativa, com parâmetros essencialmente pragmáticos e discursivos. Sendo assim, são fenômenos históricos, profundamente ligados ao social e cultural, surgindo de acordo com as necessidades e atividades socioculturais, bem como na relação com inovações tecnológicas. De fato, estas inovações tecnológicas têm possiblitado que os gêneros sejam ainda mais visuais.

Além disso, Bronckart (2006) explica que as atividades comunicativas são estabilizadas pelos gêneros textuais. Este autor nota ainda que os gêneros são conhecidos como constructos abstractos que vão ser concretizados em textos, uma vez que são modelos psicológicos encontrados na memória social e que vão ser adaptados pelo produtor textual no momento da produção do texto. Os gêneros são imprescindíveis para a realização de nossas ações comunicativas, uma vez que são reconhecidos como modelos de referência, os quais todo produtor emprega para realizar ações de linguagem. Assim, para este autor os gêneros são estabilizados na produção textual. Isto implica que, numa dada situação de produção textual, o produtor fará escolhas relacionadas com a seleção e combinação de elementos que configuram a realização semiótica, com base em um modelo aplicado na interação, isto é, a escolha do gênero. O resultado será um texto empírico no qual figura o modelo de gênero escolhido e os processos particulares da situação de comunicação.

Desta forma, a noção de texto deste autor problematiza a noção de texto dos formalistas, que reduzem o universo textual unicamente às unidades linguísticas. Para mostrar seu posicionamento, Bronckart (2006, p. 139) apresenta a seguinte definição de texto:

Não é, em si mesmo, uma unidade linguística, pois suas condições de abertura, de fechamento (e, provavelmente, de planeamento geral) não dependem do linguístico mas são inteiramente determinadas pela ação que o gerou. Essa é a razão pela qual dizemos que o texto é uma unidade comunicativa.

Em última análise, analisar os textos envolve considerá-los em seu nível epistémico e praxiológico. Isto significa que observar os modos de funcionamento implica também 
perceber os vários processos de semiotização das unidades que os compõem. Nesta mesma linha de pensamento, Bazerman (2005, p.19) complementa esta ideia ao fazer notar que analisar os textos, sua produção, circulação e ordenação é o caminho para perceber como se estruturam as atividades humanas e como organizam-se os grupos sociais.

Portanto, neste artigo, assumimos que as atividades comunicativas determinam a escolha do género, influenciando, inclusive, a função que os diferentes elementos semióticos irão ter no texto. E, sendo o texto a materialização empírica do gênero, então, na própria produção textual, encontram-se em evidência os elementos que determinam tanto o gênero escolhido quanto a atividade de linguagem em que esse gênero participa.

Além disso, defendemos que gêneros como a reportagem são reconhecidamente multimodais. O que implica dizer que em sua organização textual o não verbal interage com o sistema linguístico. Perceber como se processa esta interação é essencial para compreender o funcionamento da língua na sociedade. Esta busca por compreender essa interação tem sido uma das grandes preocupações dos teóricos que orientam seus estudos sob o enfoque da multimodalidade. Nesta linha, estão autores como Kress e van Leeuwen (2006) que estudam os gêneros a partir de uma perspectiva discursivo-semiótica. Estes autores concedem uma importante contribuição para o estudo de textos multimodais. Com efeito, um dos pontos fundamentais da teoria da semiótica social é a de que analisar o multimodal compreende considerar todos os elementos que constituem a linguagem. Assim, tornam-se defensores de congregar os elementos linguísticos e não verbais num estudo conjunto, verificando a forma como eles se articulam nos textos.

\subsection{A GRAMÁTICA DO DESIGN VISUAL: O SIGNIFICADO REPRESENTACIONAL}

Segundo Kress, Leite-Garcia e van Leeuwen (1997), a semiótica social identifica três questões no processo de caracterizar o texto multimodal. A primeira é que se deve observar como diversas formas de semiotização estão envolvidas na produção e interpretação textual. A segunda refere-se ao fato de que estas formas têm características que pertencem às culturas em que são produzidas. A terceira debruça-se na necessidade de existir um conhecimento na maneira de ler esses textos de forma que sejam coerentes e que gerem compreensões. É neste último ponto que os autores defendem ser este conhecimento ensinável por processos de letramento.

Para atingir os objetivos da semiótica social na análise do multimodal, Kress e van Leeuwen (2006) propõem um quadro teórico-metodológico chamado Reading Images: The Grammar of Visual Design ${ }^{1}$ (daqui para frente, GVD). Para Fernandes e Almeida (2008, p.12), "é hoje um dos estudos mais importantes na descrição da estrutura que organiza a informação visual nos textos".

Alicerçados no quadro teórico da Gramática Sistêmico Funcional proposta por Halliday (1978), estes autores idealizam uma "gramática" aplicada à análise do visual. De facto, o termo gramática põe em destaque as relações dos elementos de um sistema.

\footnotetext{
${ }^{1}$ Lendo imagens: a gramática do design visual (tradução nossa).
} 
Assim, na proposta da GVD, procura-se descrever as relações entre os diferentes elementos semióticos de um texto multimodal, relacionando-os com a diversidade das práticas sociais e os conhecimentos daí oriundos. A partir deste posicionamento, esses autores apresentam, dentro da perspectiva da semiótica social, um modelo de análise que também propõe três (meta)funções (representacional, interativa e composicional), que procuram atender aos aspectos comunicativos envolvidos nas imagens e que estão presentes nos gêneros. Desse modo, a representacional é responsável por indicar ações (ou eventos) que vão sendo construídos visualmente. A função interativa apresenta o tipo de relações que vai sendo construído entre os participantes. E, por fim, a função composicional é responsável pela estruturação do texto e agrupa as funções representacional e interativa.

Ainda segundo a GVD, Kress e van Leeuwen (2006) consideram a existência de dois tipos de participantes: os participantes interativos, que serão os produtores ou leitores reais do texto; e os participantes representados, que são aqueles que constituem a temática mais importante do multimodal e que são representados pelas imagens.

A função representacional indica o que está sendo apresentado pela cena comunicativa, que relações estão sendo construídas entre os elementos apresentados e em quais circunstâncias. Correlacionando-a com a metafunção ideacional, a representacional é definida na GVD como a capacidade do sistema semiótico para apresentar os objetos e suas relações no mundo social dentro de um sistema de representação. Para os autores, há dois tipos de representações feitas pela imagem: as narrativas e as conceituais.

Segundo Kress e van Leeuwen (2006), as representações narrativas podem ser identificadas pelo analista por meio de "setas" imaginárias que apontam para um movimento dentro do ato semiótico. Essas setas indicam que há um participante representado pela imagem que direciona sua ação para outro participante. Assim, a representação narrativa é identificada como ações, eventos e processos de mudança. Os vetores imaginários mostram a direcionalidade da ação. $\mathrm{O}$ participante do qual parte a ação é conhecido como ator. É dele que parte a seta com a ponta direcionada àquele que recebe a ação e que será reconhecido como meta. Os tipos de processos narrativos podem ser identificados com base nos tipos de vetores, número e tipos de participantes envolvidos. Neste artigo não nos deteremos na identificação dos tipos de processos, mas procuraremos apresentar o significado da representação narrativa na reportagem. $\mathrm{O}$ importante é deixar claro que, no ato semiótico com representações narrativas, é possível identificar agentes (aquele participante que será considerado como ator) e representações de ação (processo que é perceptível pela presença de vetor).

Ao contrário das narrativas, as representações conceituais não apresentam ação, mas representam os participantes em termos de tipos ou classes. Este tipo de representação caracteriza os participantes em termos da sua classe, estrutura ou significação. Portanto, não há presença de vetores indicando atuações dentro do ato semiótico. Kress e van Leeuwen (2006) destacam três tipos de processos nas representações conceituais, são elas: classificacional, quando há a presença de uma taxonomia que pode ser aberta ou fechada; analítico, quando apresentam uma relação entre a parte e o todo; e simbólico, quando apresentam um processo que indica aquilo que o participante é ou significa. A representação simbólica ainda pode apresentar dois tipos 
de processos: os processos atributivos, nos quais o participante é realçado por meio de seu posicionamento na imagem (ex.: tamanho exagerado); ou processos sugestivos, em que são apresentados o contorno ou a silhueta do participante. Nesse caso, a identidade ou significado é mostrado através de um traço intrínseco ao portador, sendo considerado como sua essência.

\section{A PRESENÇA DA FUNÇÃO REPRESENTACIONAL NA REPORTAGEM}

$\mathrm{Na}$ atividade jornalística, a informação, interpretação e opinião participam como elementos norteadores na construção dos chamados "fatos jornalísticos". O funcionamento desta tríade fundamenta-se em três níveis: a apresentação dos fatos (informação), a relação entre os diferentes fatos (interpretação) e o julgamento sobre estes fatos (opinião). Apesar de as fronteiras entre esses três elementos serem difusas, a ênfase dada a cada um caracteriza o texto jornalístico, segundo Medina (1988). Assim, enquanto na notícia predomina a apresentação dos fatos e nos editoriais (ou artigos de opinião) os juízos de valor, é na reportagem que a interpretação dos fatos encontra sua expressão mais desenvolvida. Ainda, segundo Medina (1988), essa interpretação baseia-se no olhar subjetivo do repórter ao escolher um foco na abordagem da descrição e observação dos acontecimentos. Essa escolha é construída tanto pelo linguístico como pelo não verbal. É na conjugação destes dois elementos que se constrói uma "narrativa" direcionada temporalmente para um hoje, apesar de tratar-se da interpretação de fatos já ocorridos numa situação anterior.

Tal como foi colocado na introdução, o presente artigo procura também ressaltar a interação entre diferentes sistemas semióticos - o verbal e o não verbal - pois é nessa inter-relação que se constrói a interpretação do texto. Além da interação entre os diferentes sistemas semióticos, também ocorre, dentro do texto, a interação entre os diferentes elementos não verbais que compõem o chamado ato semiótico. Isto significa que a interpretação também será fruto da inter-relação entre as próprias representações narrativas e conceituais.

A tabela 1 mostra a quantificação das representações encontradas nas reportagens analisadas:

Tabela 1 - Número de representações encontradas na reportagem

\begin{tabular}{l|r|r}
\hline Revistas & Visão & Sábado \\
\hline Narrativas & 7 & 14 \\
\hline Conceituais & 28 & 26 \\
\hline
\end{tabular}

Fonte: elaboração própria.

Esta tabela é constituída pelo número de representações encontradas nas reportagens aqui analisadas. As representações narrativas são aquelas que, pela imagem visualizada, indicam algum tipo de ação. As representações conceituais não apresentam ação. Em uma primeira conclusão, a partir da leitura da tabela, podemos observar que o 
número de representações conceituais é superior ao de representações narrativas. E ainda que o número de representações conceituais na duas revistas é mais ou menos equilibrado, mas a revista Sábado utiliza o dobro de representações narrativas da revista Visão. De fato, cada uma destas representações apresenta um papel dentro do texto, que será consolidado na relação com o verbal, tal como veremos na análise que segue. Pela impossibilidade de colocar a reportagem inteira, apresentaremos apenas algumas páginas em que centraremos nossa análise.

Ainda antes de prosseguirmos com a análise, é importante clarificar que, como investigadores/leitores, de fato, não temos total acesso às intenções do produtor textual. Assim, nosso papel, enquanto analistas do texto/discurso, consiste em procurar recuperar essa intenção a partir de pistas proporcionadas pelo gênero no momento da leitura. É na interação entre o texto e o leitor que se insere a questão do(s) objetivo(s) da leitura. Nosso objectivo neste artigo é tentar mostrar o percurso interpretativo a partir das identificações semióticas trazidas pelas reportagens. Afinal, para Koch (2007, p.19), "são, pois, os objetivos do leitor que nortearão o modo de leitura, em mais tempo ou em menos tempo; com mais atenção ou em menos atenção; com maior interação ou com menor interação". É de ressaltar que a perspectiva apresentada por Koch (2007) também é considerada pela semiótica social proposta por Kress e van Leeuwen (2006). No momento em que os autores falam na intenção (objetivo) tanto do produtor como do observador/leitor de escrever e ler respectivamente, assumem, com isso, seu papel enquanto participante da interação do ato semiótico. Portanto, podemos afirmar que, em nossa perspectiva, o processo de análise textual enquanto receptores do texto deve ser considerado como um processo de reconhecimento dos objetivos e descrição da construção textual para o alcance desses objetivos.

Vejamos agora a análise das reportagens. Apresentaremos como primeiro exemplo a reportagem da revista Visão publicada na semana de 05/11/2015 a 11/11/2015.

A reportagem, intitulada $O$ Amigo, $O$ dinheiro e as Escutas, tem sete páginas e caracteriza-se por ser uma reportagem de capa, tendo assim grande destaque. $O$ tema trata sobre transferências de dinheiro entre o ex-primeiro-ministro de Portugal, José Sócrates e o empresário Carlos Santos Silva, desde o ano de 2013. A alegação de que o empréstimo concedido pelo empresário na verdade seria um pagamento do empresário em troca de favores prestados por Sócrates constitui a base do processo de investigação. Apesar de não saberem o motivo do pagamento, a acusação alega o alto valor de empréstimo e a sua não devolução como indícios de existência de corrupção.

$\mathrm{Na}$ figura 1, apresentamos a capa da revista, uma vez que todo percurso interpretativo de uma reportagem deste tipo começa exactamente pela capa, sendo considerado um dos atrativos para o interesse no consumo da revista. Visualmente, a capa apresenta o ex-primeiro-ministro a caminhar em uma estrada de dinheiro (notas de 500 euros). Nesta visualização, detectámos tanto a representação narrativa, que mostra o exprimeiro-ministro a caminhar, quanto a representação conceitual, representada pelas notas de dinheiro. Qualquer representação que mostre dinheiro indicia para seu valor social. Isto é, quando o produtor apresenta visualmente notas de dinheiro, é sinal de que procura colocar em evidência um símbolo de alto valor social. Vemos ainda que o repórter juntou a representação do dinheiro (e de notas de 500 euros que são de alto valor) com a ação de caminhar. 


\section{Figura 1 - Capa da reportagem de Visão}

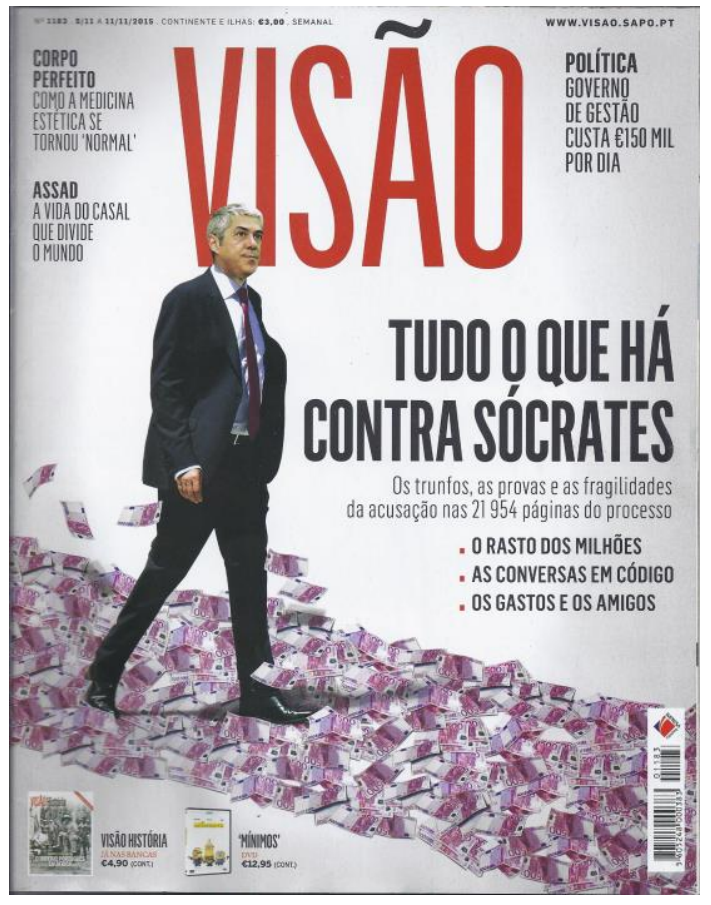

A junção destas duas representações pode levar o leitor a interpretar que o primeiroministro possui muito dinheiro, a ponto de poder caminhar sobre ele. Essa visualização cria significados sobre o possível envolvimento do ator social da imagem, Sócrates, em esquemas de corrupção (que lhe permite ter muito dinheiro). A capa em si já é uma representação que pode induzir a pensar na culpabilidade do agente envolvido (Sócrates). Esta ideia é reforçada pelo título da capa "Tudo o que há contra Sócrates", ou seja, a reportagem apresentará como temática o que há contra o agente, mostrando evidências que levam o leitor a pensar na culpa do arguido. Além da imagem do caminhar sobre o dinheiro, vemos ainda o uso, no título, do negrito e de letras maiúsculas. O negrito e a letra maiúscula são, segundo Kress e van Leeuwen (2006), indicadores de algum um grau de saliência. Esse uso parece reforçar a construção de significados da imagem narrativa de caminhar. A par disso, também parece ocorrer um reconhecimento do papel social dos agentes envolvidos, isto é, do político Sócrates na reportagem, o que parece que irá influenciar no discernimento sobre o tema. Isto é, enquanto leitores, conhecedores do contexto político português, reconhecemos pela imagem (a fotografia de José Sócrates) que o personagem representado é uma figura pública que teve um papel social importante e que, por isso mesmo, incute a interpretação de que caminhar sobre o dinheiro seja considerado, a partida, como um indício que o culpabiliza. Desse modo, essa co-relação feita pelo leitor entre o papel social do agente e a quantidade de dinheiro cria significados no âmbito interpretativo. Podemos mesmo afirmar que a representação conceitual realizada na identificação da fotografia do personagem traz informações sobre os participantes e sua representação em termos do que significam ou do que são. Esta representação estabelece, assim, a identidade desse participante, fornecendo inferências para a constituição do tema. Assim, a capa qualifica-se, no percurso interpretativo, como o primeiro contato do leitor com o gênero reportagem. 
Esta interpretação será reforçada no seguimento da reportagem; vejamos as duas primeiras páginas, 40 e 41 :

Figura 2 - Revista Visão 5 a 8/11/15 - p. 40-41

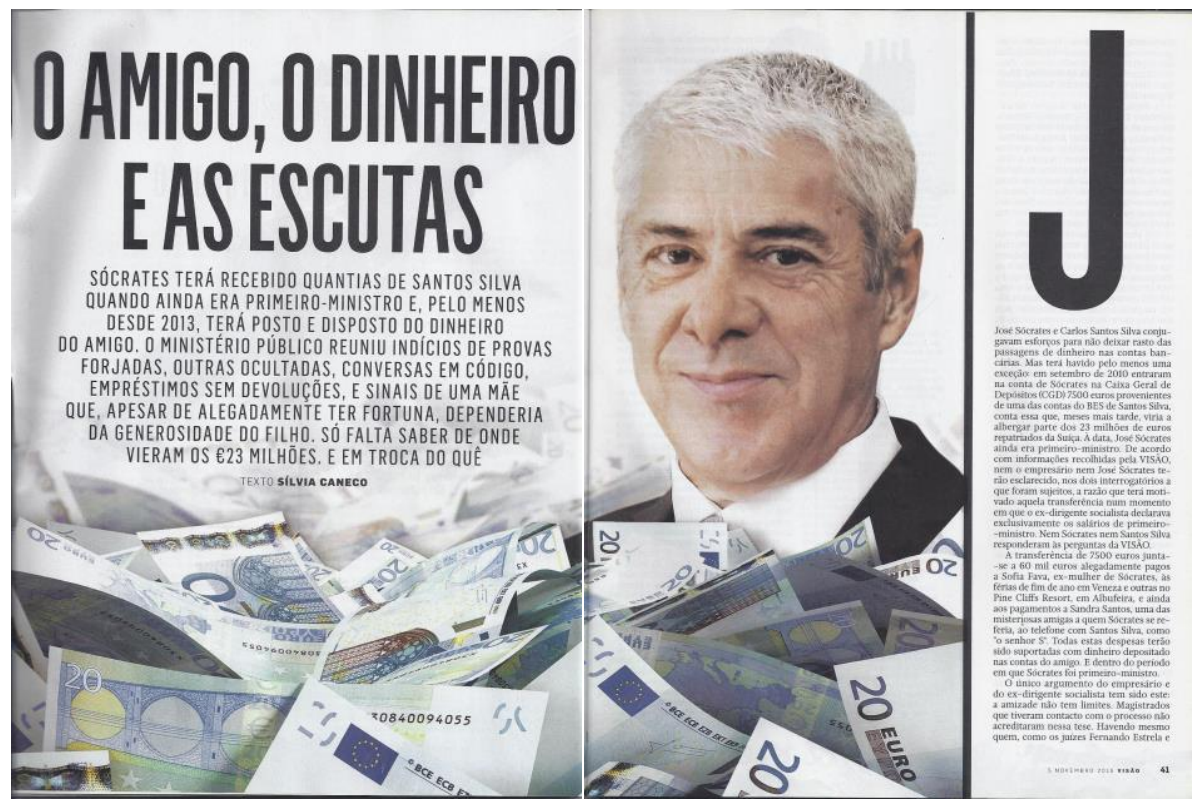

A primeira imagem interna da reportagem é uma representação conceitual que irá retomar o significado já construído pela capa. Nessa página, o ex primeiro-ministro é representado como tendo dinheiro até o pescoço. A imagem mostra um grande número de notas (de 20 euros), ficando de fora apenas o rosto que interage com o leitor através do olhar e de seu sorriso. Ao lado de seu rosto, temos o título, $O$ Amigo, $O$ dinheiro e as Escutas, e o lead. O mar de notas ocupa toda a zona inferior das duas páginas. A própria imagem parece já responder algumas questões do lead, pois não só participa da progressão temática, como também, e, principalmente, induz inferências no processo de leitura.

É sabido que o lead responde a seis questões: o que, quem, quando, por que, como e onde. E, com isso, o lead procura ter o objetivo de apresentar um resumo da reportagem. Neste exemplo, essa parte, mais do que apresentar um resumo da reportagem, também parece reforçar o significado de indício de corrupção por parte do ex-primeiro ministro. Em baixo, apresentaremos as perguntas e respostas encontradas no lead e as possíveis inferências entre parenteses. Assim, temos:

a) O que: terá recebido (altas) quantias de Santos Silva, (há indícios de não ser um mero empréstimo);

b) Quem: Sócrates (reconhecido pela imagem e referenciado na parte verbal pelo nome);

c) Quando: quando ainda era primeiro-ministro e, pelo menos, desde 2013;

d) Porque: terá posto e disposto do dinheiro do amigo. Só falta saber de onde vieram os 23 milhões em troca de quê; 
e) Como: O ministério público reuniu indícios de provas forjadas, outras ocultadas, conversas em código, empréstimo sem devoluções, e sinais de uma mãe que, apesar de alegadamente ter fortuna, dependeria da generosidade do filho;

f) Onde: em Portugal

O que fica por responder e que aparece assumido como questionamento no lead é a razão deste "empréstimo" e perceber, realmente, de onde veio o dinheiro. Portanto, a interpretação a que o leitor será levado é da culpabilidade de Sócrates, apesar de ainda estar a decorrer o processo. Para esta interpretação, a representação conceitual terá um papel fundamental, pois a relação que o leitor fará a partir do visual é entre o papel social do personagem representado com o simbolismo do "mar" de dinheiro. Esta relação será reforçada pelo título: O Amigo (aquele que "deu" o dinheiro), o Dinheiro (a quantia elevada) e as Escutas (a prova da culpa).

Outro exemplo de representação conceitual, do tipo analítico, uma vez que apresenta uma infografia para esclarecer o percurso do dinheiro, que induz a significação da culpabilidade, encontra-se na página 46. E que apresentamos na figura 3:

\section{Figura 3 - Reportagem de Veja em análise - p. 46}

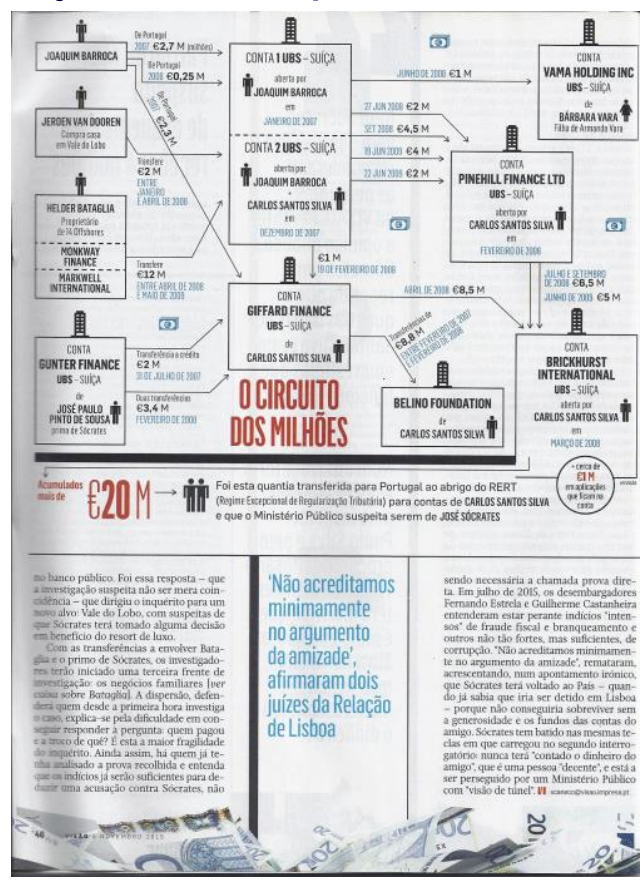

Esse esquema tem como título $O$ Circuito dos Milhões. Visualizamos o título na cor vermelha e de modo centrado, o que parece apresentar um alto grau de saliência. Isso, aliado ao uso da preposição "de" mais o artigo definido "os", mostra que o dinheiro é conhecido, ou seja, o uso do determinante "dos" $(\mathrm{d}+\mathrm{os})$ reforça a ideia de que o circuito dos milhões refere-se ao dinheiro do alegado empréstimo do empresário "Carlos Santos Silva" a Sócrates. O circuito ocupa metade da página e, logo abaixo da infografia, aparece em destaque o discurso relatado "não acreditamos minimamente no argumento da amizade" dita por dois juízes da Relação de Lisboa, os quais participam do processo. Esta representação conceitual, aliada à função composicional (saliência pela cor e posição na página), parece procurar induzir no leitor a crença de culpa do arguido. 
Assim, essa visualização parece encaminhar o leitor para uma interpretação de culpa. No entanto, é de pôr em evidência que o processo ainda está a decorrer e isso leva o jornal a não assumir publicamente a culpa do arguido, para poder manter a "objectividade" que é suposto uma reportagem ter. Segundo o Direito português, quando se instaura um processo e o envolvido é considerado arguido, a culpa só é determinada depois de transitado todo o processo. Dito de outro modo, quando existem indícios que caracterizam uma pessoa de ter cometido um delito, essa pessoa é considerada inocente até que seja confirmada, em sentença, sua culpa. Só depois da conclusão do processo o arguido poderá passar a ser considerado condenado. Nesse exemplo, o ex-primeiro ministro é um arguido apenas e, portanto, deve ser considerado como inocente até o fim do processo ou julgamento.

Ciente desta norma imposta pelo Direito, o repórter deverá se salvaguardar e, consequentemente, também o jornal/revista, uma vez que correm o risco (o repórter e a revista Visão) de serem processados por tentativa de indiciar culpa. Desse modo, apesar de o uso das representações semióticas parecer criar a interpretação de culpa, o produtor textual utiliza estratégias na semiotização verbal para dar um grau de incerteza ao seu discurso. Entre essas estratégias está, por exemplo, o uso de um tempo composto que indica um futuro incerto, tais como, "terá recebido", "terá havido", "terá motivado". Essa construção verbal é recorrente em toda a reportagem. O objetivo do repórter é colocar suas afirmações no campo do "incerto", da "dúvida", apesar de visualmente parecer procurar levar o leitor para um caminho interpretativo oposto.

Vejamos agora o segundo exemplo, retirado da revista Sábado. Tal como o exemplo 1, começaremos nossa análise pela capa da revista (figura 4):

Figura 4 - Capa da revista Sábado - 12-18/11/2015]

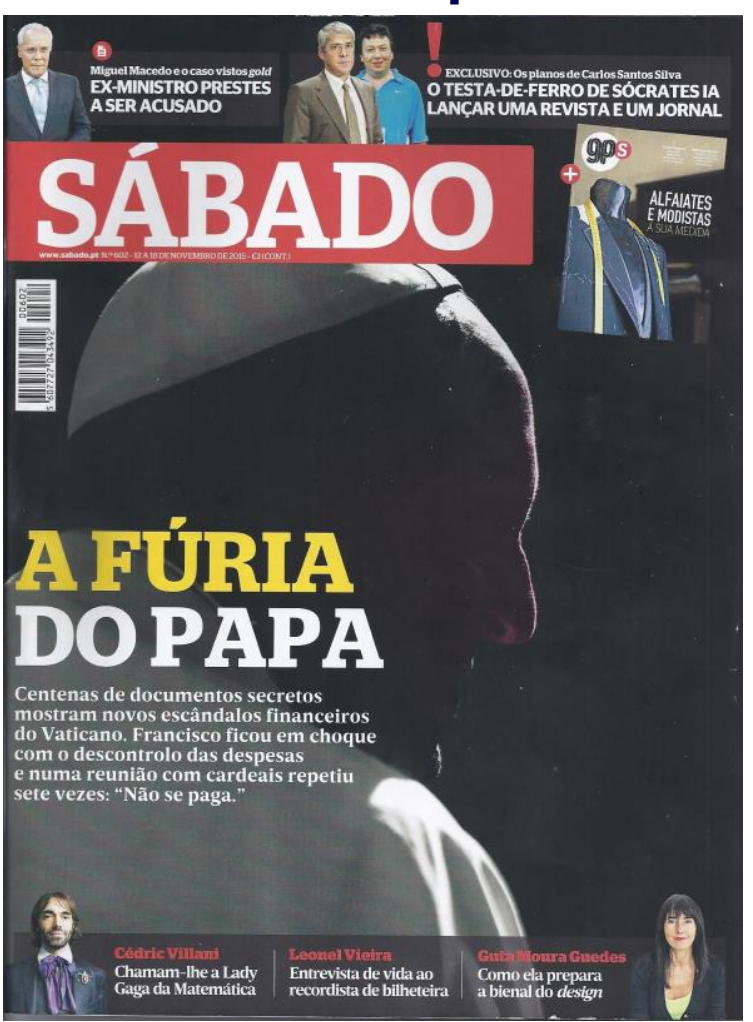


Esta reportagem foi publicada na semana de 12 a 18 de Novembro de 2015. A reportagem, intitulada A luta do Papa contra os Escândalos do Dinheiro, tem oito páginas, e, tal como a reportagem de Visão, caracteriza-se por ser uma Grande Reportagem de capa. O texto verbal que se encontra na capa dá pistas ao leitor sobre a temática que será tratada na reportagem. Na capa, podemos ler: "Centenas de documentos secretos mostram novos escândalos financeiros do Vaticano. Francisco ficou em choque com o descontrolo das despesas e numa reunião com cardeais repetiu sete vezes: 'não se paga'." Assim, deduzimos que o tema terá dois focos: os novos escândalos financeiros no Vaticano e o desconhecimento do Papa. Contudo, a capa utiliza o termo "ficou em choque". Isto parece revelar que não se trata apenas de não conhecer, mas da perplexidade diante da descoberta. Na verdade, o foco da notícia parece ser o de evidenciar a luta do Papa Francisco contra os excessos de despesa da Santa Fé. Desse modo, as representações da reportagem parecem ter o objetivo de salientar dois aspectos: a) o desconhecimento do Papa; b) as altas despesas do alto clero (cardeais, bispos, arcebispos, patriarcas, bispos, e alguns tipos de sacerdotes ).

Neste sentido, a capa traz exatamente o perfil do atual papa da igreja Católica Romana, o Papa Francisco, envolto em sombra. Reconhecemos o Papa principalmente pelo traje comum, bata usada sempre que o papa não está em celebrações e, principalmente, pela cor do traje, o branco, que é a cor usada na igreja católica apenas pelos papas. Conseguimos, assim, visualizar o solidéu, acessório usado pelos papas, bispos, cardeais e abades, dependendo da hierarquia; neste caso o solidéu é branco, indicando ser do papa. E também visualizamos o amito, peça que cobre os ombros e pescoço, significando a disciplina dos sentidos e dos pensamentos. A contrastar com o branco do solidéu e do amito temos o negro que envolve a face e o fundo do participante representativo. Esta sombra é transpassada por um feixe de luz que incide sobretudo no alto da cabeça do Papa. Esta luz pode representar o Papa sendo iluminado ou abençoado, pois a luz vem do alto (para as religiões, é o lugar onde fica Deus e de onde vem toda a iluminação). Desse modo, temos dois tipos de representação conceitual simbólica, a roupa juntamente com a cor que caracteriza o papa e o escuro que envolve sua figura. Podemos, então, concluir que a representação vai também construir significados que irão corroborar a temática do desconhecimento do papa acerca das contas do clero e de seu descontentamento com a descoberta. Esta ideia volta a ser recuperada ao longo da reportagem. Vejamos as duas páginas iniciais (figura 5):

As representações conceituais nestas duas primeiras páginas da reportagem vão retomar os mesmos significados já indicados na capa. Aqui mostra-se o perfil do papa, agora, por completo, mas continua envolvido pelo negro. É no contraste que visualmente se apresenta a ideia da discordância do papa em relação aos gastos da Igreja. Esta discordância é apresentada linguisticamente no lead, quando o repórter escreve "[...] Francisco demorou pouco a perceber que os gastos da Igreja estavam "fora de controlo". Mas está longe de vencer esta guerra." A própria alusão à palavra "guerra" retoma o título "A luta do Papa contra os escândalos do dinheiro". Assim, o autor do texto não só coloca o Papa Francisco como contrário aos gastos excessivos, mas, sobretudo, revela o desejo do Papa de combater estes abusos do clero. No seguimento do texto, o primeiro parágrafo começa por relatar os excessos da Cúria em Portugal ao referir os três portugueses no top 
dos membros com os maiores palacetes. Em contraste, o repórter inicia o segundo parágrafo com a conjunção "enquanto isso" e passa a relatar que o "Papa Francisco, depois de eleito em Março de 2013, dispensou os luxos dos seus antecessores". Esta contradição, tal como já referimos, é também representada visualmente.

\section{Figura 5 - Reportagem de Sábado em análise - p. $42-43$}

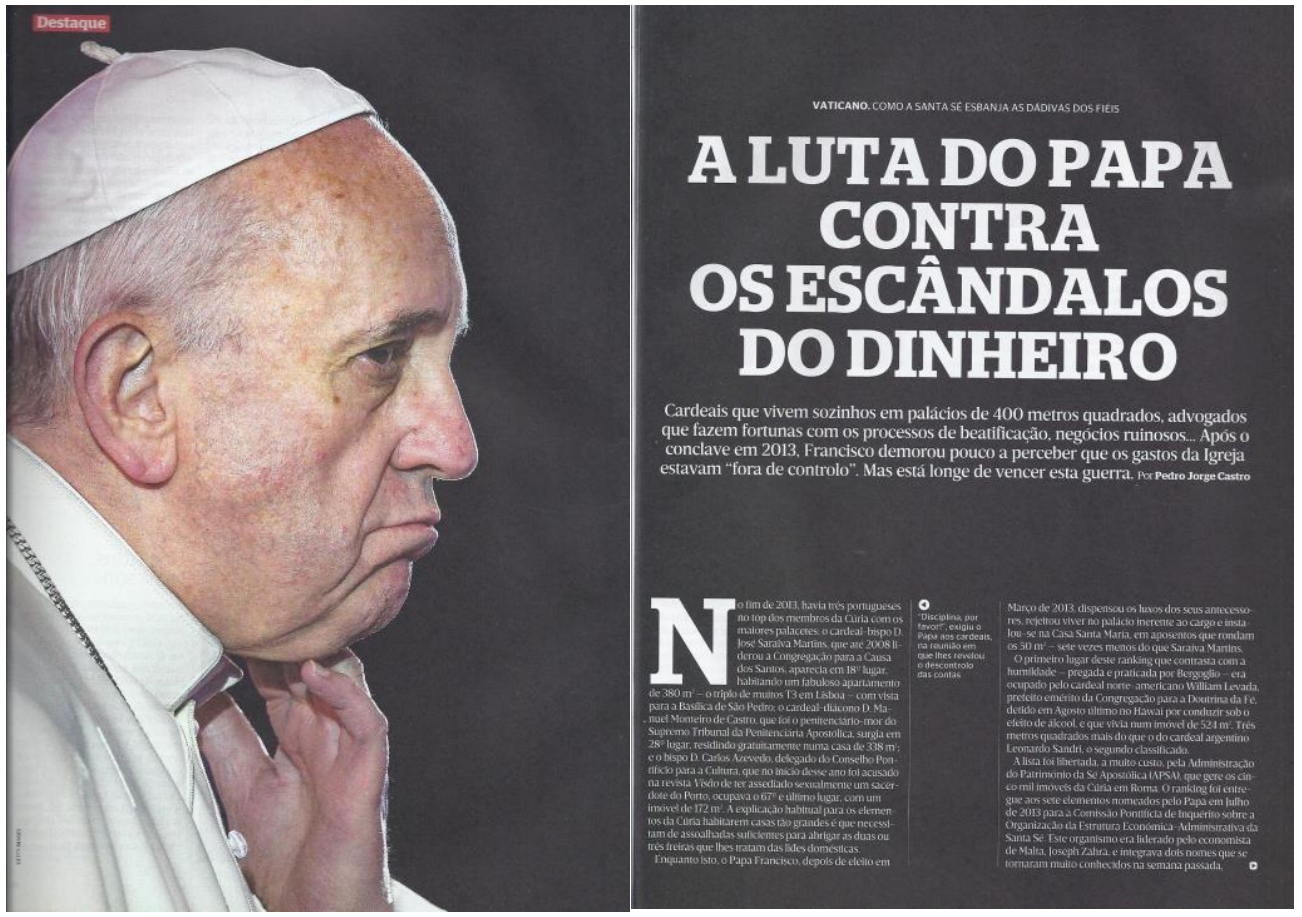

O contraste entre as ideias do Papa e o clero da Igreja com relação aos gastos financeiros também vai ser reforçado pelo uso da representação narrativa. Na página 46, há uma fotografia localizada no canto superior direito que mostra um cardeal a ser servido por um funcionário que coloca a capa sobre seus ombros. Tal ação, que expressa uma representação narrativa, parece mostrar uma atitude de subserviência, de servilismo. $O$ que contrasta com a escolha do Papa de ter uma vida mais humilde, tal como relata o repórter no trecho "[...] que contrasta com a humildade - pregada e praticada por Bergoglio (Papa)". Vejamos a imagem em questão:

Ainda nesta página, ao lado da fotografia anteriormente comentada, vemos outra representação conceitual do tipo Classificacional. A imagem apresenta as dez maiores fontes de prejuízo por ordem do que dá mais para o que dá menos prejuízo. O significado deste esquema, juntamente com a fotografia, será ainda reforçado pela frase "Os custos com funcionários cresceram 30\%. 'Há aí qualquer coisa de errado' avisou o Papa”, que se encontra ao fundo da página com saliência pela cor azul. Além disso, é recorrente nesta reportagem a fala do próprio Papa como, por exemplo, no início do primeiro parágrafo que fica por baixo do esquema, a frase "Não se paga', repete o Papa sete vezes". Desse modo, o repórter vai construindo a sua narrativa, procurando levar o leitor a interpretar, tanto pela leitura do verbal quando do visual, o tema do contraste entre aquilo que o Papa vive e ensina e as despesas fora de controle do Vaticano. 


\section{Figura 6 - Reportagem de Sábado em análise - p. 46}

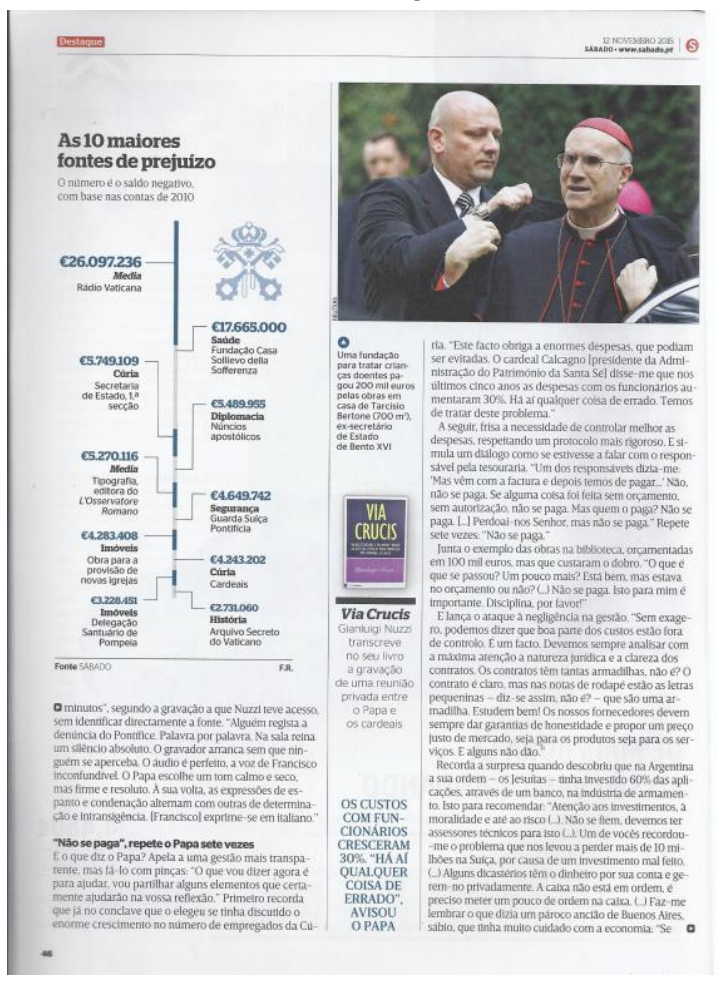

Outra imagem usada para contrastar com a humildade do Papa é o uso da mitra pelo monsenhor Giuseppe Sciacca. A mitra é usada apenas quando há algum evento em particular. O uso deste tipo de chapéu em Roma começou no século 10 e era um símbolo que diferenciava o Papa dos outros sacerdotes. Esta peça ainda é usada na igreja e alude à santidade e à coroa de glória. Hoje em dia, é usado também por abades, bispos, arcebispos e cardeais (figura 7, mais adiante).

Ao apresentar o monsenhor com este tipo particular de chapéu, o autor do texto o diferencia da roupa simples em que Francisco constantemente aparece nessa reportagem. Assim, há uma intenção de associar o monsenhor ao símbolo que manifesta o poder da igreja ao representar a "coroa de glória". Visualmente, é construída uma interpretação de humildade do Papa contra a "altivez" do monsenhor que também está envolvido no escândalo do Vaticano.

Assim, o repórter constrói o seu ponto de vista, fazendo sempre um paralelo com o descontentamento do Papa sobre as altas despesas do clero. O discurso do Papa é repetido com citações, tais como: "Há qualquer coisa de errado. Temos que tratar deste problema" (p. 46), "Perdoai-nos Senhor, mas não se paga" (p. 46). E ainda com esclarecimentos do próprio repórter, como "Francisco ficou furioso" (p. 44), "o Papa passa ao ataque" (p. 44). Esse ponto de vista é uma construção discursiva observada não apenas pelo verbal mas também pelo visual. Os dois modos semióticos vão se complementar para criar a significação no texto. Como diz Kress (1997, p.51): "Parece evidente estarmos perante uma época que assiste a uma mudança significativa da relativa valoração, assim como da carga quantitativa, dos vários modos semióticos, através dos quais uma sociedade produz e reproduz os diversos significados." 
Figura 7 - Reportagem de Sábado em análise - p. 50

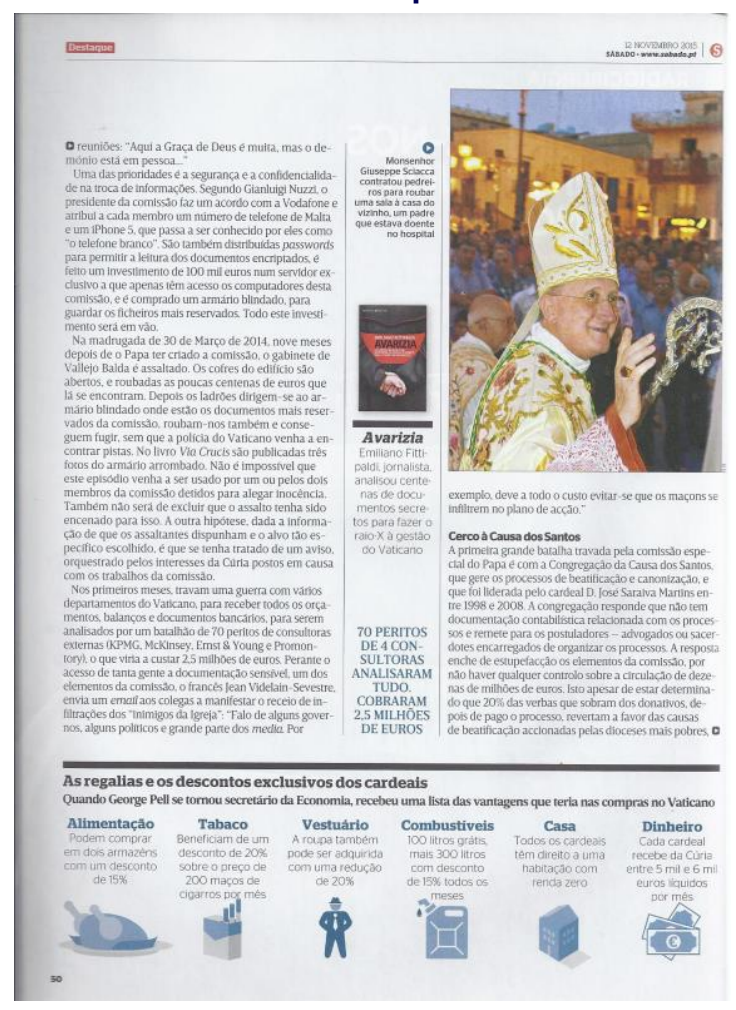

4 NOTAS CONCLUSIVAS

De fato, a partir das análises apresentadas neste artigo, podemos afirmar que o género se relaciona com as práticas sociais. Isto é, as características sociocomunicativas presentes nos gêneros vão variar de acordo com a função do gênero e com as escolhas do autor do texto para atender a essa função. No caso da reportagem, a função relaciona-se com a interpretação do repórter sobre fatos que ocorrem na sociedade. Esta característica, em particular, vai ser construída pelo leitor através dos significados perceptíveis na relação do verbal com o visual.

Sem dúvida, é na atividade de linguagem, neste caso a atividade jornalística, que o gênero é convocado, apresentando uma relação de modo dinâmico, variando de acordo com o momento social, cultural e histórico. Assim, diferente da notícia que tem um carácter mais informativo, a reportagem apresenta um posicionamento ainda mais subjectivo. Essa relação é perceptível na atividade do repórter de apresentar seu ponto de vista sobre o acontecimento. Desse modo, a ação de linguagem do repórter é uma construção subjectiva, tal como demonstrado na análise dos textos.

Ainda com relação às reportagens, as conclusões revelaram que o uso das representações conceituais reforça a função de construir a interpretação do repórter, dando um carácter mais pessoal na escolha das representações semióticas. Por outro lado, o uso das representações narrativas parece ter a função de construir a história visualmente, apresentando cenas que, de alguma forma, participaram na história construída pela reportagem. Mas isso não impede que essa participação ou a escolha de determinada ação em detrimento de outra não tenha um forte subjectivismo, como foi mostrado aqui. 
Também podemos observar que a subjetividade do repórter na apresentação do tema se revela particularmente profícua quando usa a interacção entre os diferentes elementos semióticos. Seja verbalmente ou apenas visualmente, o repórter procura levar o leitor a partilhar de seu ponto de vista, construindo, para isso, uma argumentação multimodal.

\section{REFERÊNCIAS}

BAZERMAN, C. Gêneros textuais, tipificação e interação. Org. Angela P. Dionisio e Judith C. Hoffnagel. São Paulo: Cortez, 2005.

BRONCKART, J.-P. Genre de textes, types de discours et « degrés » de Langue. Revue Texto! Janvier, vol. XIII, n. 1, 2008. Disponível em: <http://www.revuetexto.net/docannexe/file/86/bronckart_rastier.pdf $>$.

Atividade de linguagem, discurso e desenvolvimento humano. Org. Anna Rachel Machado e Maria de Lourdes Meirelles. Campinas: Mercado de Letras, 2006.

Atividades de Linguagem, textos e discursos. Por um interacionismo sócio-discursivo. São Paulo: Editora da PUC-SP, EDUC, 1999.

CARDOSO, J. A imagem como recurso persuasivo da propaganda. In: ALMEIDA, D. (Org.).

Perspectivas em Análise Visual : do fotojornalismo ao blog. João Pessoa: UFPB, 2008.

COUTINHO, M. A. Para uma linguística dos gêneros de texto. Diacrítica, Braga, v. 19, n. 1, 2005.

Texto (s) e competência textual. Lisboa: FCG-FCT, 2003.

FERNANDES, J.; ALMEIDA, D. Revisitando a Gramática Visual nos cartazes de guerra. In: ALMEIDA, D. (Org.). Perspectivas em Análise Visual: do fotojornalismo ao blog. João Pessoa: Ed. UFPB, 2008.

HALLIDAY, M. A. K. Language as Social Semiotic. The social interpretation of language and meaning. London: Edward Arnold, 1978.

KRESS, G. Considerações de carácter cultural na descrição linguística: para uma teoria social da linguagem. In: PEDRO, E. R. (Org.). Análise Crítica do Discurso. Lisboa: Caminho, 1997.

KRESS, G.; van LEEUWEN, T. Reading Images: The Grammar of Visual Design. 2. ed. London: Routledge, 2006.

KRESS, G.; LEITE-GARCIA, R.; VAN LEEUWEN, T. Discourse Semiotics. In: Van Dijk, T. (Ed.). Discourse as structure and process: Studies a Multidisciplinary Introduction. Série Discours: Sage Publication, v. 1, p. 257-291, 1997.

LEAL, A. A organização textual do gênero cartoon: aspectos linguísticos e condicionamentos não linguísticos. 2011. 462f. Tese (doutorado em Linguística) - Faculdade de Ciências Sociais e Humanas, Universidade Nova de Lisboa, Lisboa, 2011. Disponível em: <http://run.unl.pt/handle/10362/6646> A construção da temporalidade no texto multimodal. Cadernos de Linguagem \& Sociedade, v. 17, n. 1, p. 53-69, 2016. Disponível em: <http://periodicos.unb.br/index.php/les/article/view/18243/13646>.

MACHADO, A. R. A perspectiva interacionista sociodiscursiva de Bronckart. In: MEURER, J.L; BONINI, A; MOTTA-ROTH, D. (Org.). Gêneros: teoria, métodos, debates. São Paulo: Parábola Editorial, 2005. p. 237-259.

MARCUSCHI, L. A. Gêneros textuais: definição e funcionalidade. In: DIONÍSIO, A. P.; MACHADO, A. R.; BEZERRA, M. A. Gêneros textuais e ensino. Rio de Janeiro: Editora Lucerna, 2002. p. 19-36.

MEDINA, C. Notícia: um produto à venda. São Paulo: Summus Editorial, 1988.

THOMPSON, G. Introducing Functional Grammar. 2. ed. New York: Hodder Arnold, 2004.

Recebido em: 07/08/17. Aprovado em: 14/05/18. 
Title: Semiotic representations in the genre News Report in Portuguese magazines Author: Audria Albuquerque Leal

Abstract: This paper aims to study the semiotics representations of the News Report genre. Thereunto, it analyzes two texts of this text genre of two Portuguese magazines: Visão and Sábado. For this analysis it follows the theoretical proposals of the Socio-discursive Interactionism and The Social Semiotics, including the methodological framework of The Grammar of Visual Design. Therefore, the current paper seeks to take into account the role of the nonverbal in the genre News Report and its relation to the social function of this genre. The results indicate that the meanings of representations are constructed from the social practices to meet the communicative function of the genre.

Keywords: Text. Multimodality. Genre. Social semiotics. Socio-discursive interactionism.

Título: Representaciones semióticas en el género reportaje en revistas portuguesas

Autora: Audria Albuquerque Leal

Resumen: Este artículo tiene el objetivo de estudiar representaciones semióticas en el género reportaje. Para ello, analiza dos textos de este género textual de dos revistas portuguesas: Visão y Sábado. Para esto análisis, sigue propuestas teóricas del Interaccionismo Socio-discursivo y de la Semiótica Social, incluso el cuadro metodológico de la Gramática del Design Visual. De esta forma, el presente artículo procura considerar el rol del no verbal en el género Reportaje y su relación con la función social del género. Los resultados indican que los significados de las representaciones son construidos desde las prácticas sociales para atender la función comunicativa del género.

Palabras-clave: Texto. Multi-modalidad. Género. Semiótica social. Interaccionismo sociodiscursivo.

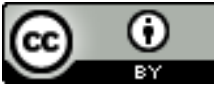

Este texto está licenciado com uma Licença Creative Commons Atribuição 4.0 Internacional. 